\title{
ANÁLISE DISCURSIVA DAS PRÁTICAS DE EDUCAÇÃO AMBIENTAL NO ENSINO FUNDAMENTAL: ESTUDO DE CASO EM UMA ESCOLA MUNICIPAL EM PALMAS (TO)
}

\author{
Jonatas Gomes Duarte ${ }^{1}$ \\ Hilda Gomes Dutra Magalhães ${ }^{2}$ \\ Luiza Helena Oliveira da Silva ${ }^{3}$
}

RESUMO: Este estudo buscou verificar como a Educação Ambiental (EA) se concretiza na escola, mediante a análise dos discursos de professores e alunos de uma escola municipal de Palmas (TO), a partir das propostas de políticas públicas educacionais, utilizando o enfoque da Análise do Discurso (AD) e da EA. Constatou-se que, apesar dos sujeitos da pesquisa atribuírem uma grande importância ao Meio Ambiente e expressarem um grau considerável de consciência ambiental, a prática ainda é insuficiente, e embora venha surtindo efeitos aos poucos, precisa ser melhor sistematizada no espaço escolar, com a participação tanto da escola quanto da comunidade.

Palavras-chave: Educação Ambiental; Políticas Públicas Educacionais; Análise do Discurso.

\footnotetext{
${ }^{1}$ Mestre em Ciências do Ambiente, pela Universidade Federal do Tocantins. Graduado em Letras pela mesma instituição.

${ }^{2}$ Doutora em Teoria da Literatura, com pós-doutorado na Universidade de Paris III e na EHESS/França. Professora da Universidade Federal do Tocantins.

${ }^{3}$ Doutora em Letras pela Universidade Federal Fluminense. Professora Adjunta da Universidade Federal do Tocantins - Curso de Licenciatura em Letras e Mestrado em Ensino de Língua e Literatura.
}

Revbea, Rio Grande, V. 8, № 1:30-41, 2013. 


\section{INTRODUÇÃO}

A Educação Ambiental (EA) tem sido um instrumento cada vez mais requisitado para a efetivação de programas que contribuam para o surgimento de sociedades sustentáveis. No ensino formal, ela deve se apresentar como um processo participativo, visando a cultivar valores que conduzam a uma convivência harmoniosa do homem com o ambiente, compreendido não só como o ambiente natural (aspectos físicos e biológicos), mas também como um ambiente social (LEFF, 2001). Ademais, importa citar o que estabelece a Constituição Federal Brasileira em seu Art. 225:

Todos têm direito ao meio ambiente ecologicamente equilibrado, bem de uso comum do povo e essencial à sadia qualidade de vida, impondo-se ao Poder Público e à coletividade o dever de defendê-lo e preservá-lo para as presentes e futuras gerações (BRASIL, 2006, p.36).

Todavia, nota-se que as ações de EA ainda são de modo geral insipientes, com o agravante de ser da mesma forma tratada nas instituições escolares, as quais têm demonstrando pouca eficácia no enfrentamento dos problemas ambientais que se alastram em escala global. É fato que a Educação Ambiental enfrenta vários obstáculos na inserção na escola, o que alerta para a necessidade e a urgência de se realizarem pesquisas que possam contribuir para a compreensão dos problemas acerca de sua efetivação no espaço escolar.

Em função disso, emerge uma questão: Quais os motivos desta ocorrência, uma vez que existe uma política nacional em EA e uma legislação que institui a obrigatoriedade da mesma no ensino formal? Nesse contexto, esta pesquisa se propõe a analisar discursos em confronto em relação à temática ambiental no interior da escola, na tentativa de compreender as diferentes perspectivas ideológicas que se apresentam nas práticas de EA no ensino formal, fornecendo dados que poderão contribuir para se responder à questão proposta e para o aprimoramento da mesma no seio escolar.

Neste estudo, iremos utilizar a Análise do Discurso (AD) da Escola Francesa edificada no final dos anos 60, por Michel Pêcheux, a AD tem como seu objeto o discurso, considerado como "efeito de sentido entre locutores" (PÊCHEUX, 1995, p.91).

$\mathrm{Na}$ análise das questões que edificam o ensino/aprendizagem de EA no ensino formal, o que está em questão é a inscrição desse dizer em uma dada formação discursiva, entendida como aquela que vem para nomear o lugar central em que discurso e ideologia se relacionam (COSTA, 2009).

Para fins desta pesquisa, entende-se que EA é: 
(...) os processos por meio dos quais o indivíduo e a coletividade constroem valores sociais, conhecimentos, habilidades, atitudes e competências voltadas para a conservação do meio ambiente, bem de uso comum do povo, essencial à sadia qualidade de vida e da sustentabilidade. (BRASIL, 2006, p.1).

Partimos do pressuposto de que a EA na escola formal, institucionalmente estabelecida, deve proporcionar uma educação de qualidade que vise promover o ensino de princípios e valores que possam conduzir os alunos a conviver de maneira harmônica com o ambiente e com as espécies que habitam o planeta, promovendo uma relação saudável entre homem/natureza.

\section{METODOLOGIA}

No que se refere aos procedimentos metodológicos, a pesquisa coletou dados documentais da Escola e analisou o Projeto Político Pedagógico (PPP) e fez-se observações presenciais em sala de aula em quatro turmas do ensino fundamental $2^{\circ}$ ano, $4^{\circ}$ ano, $6^{\circ}$ ano e $9^{\circ}$ ano. Além destes, para analisar os discursos relacionados às práticas educativas na EA brasileira, foram realizadas interfaces com documentos nacionais considerados como referência, tais como os Parâmetros Curriculares Nacionais sobre Meio Ambiente e Saúde, de 1a a 4⿳亠丷a séries (BRASIL, 1997), os Parâmetros Curriculares Nacionais sobre os Temas Transversais, incluindo Meio Ambiente, de $5^{\text {a }}$ a 8 $^{\text {a }}$ (BRASIL, 1998a), os Parâmetros Curriculares Nacionais: terceiro e quarto ciclos do ensino fundamental (BRASIL, 1998b). PRONEA (BRASIL, 2005) e a Política Nacional de Educação Ambiental - Lei no 9.795 (BRASIL, 1999).

Para configurar a amostra da pesquisa, a mesma aplicou questionários a 36 professores, obtendo retorno de 16 deles. Foram aplicados, às series selecionadas, 108 questionários assim distribuídos: 33 no $4^{\circ}$ ano, 38 no $6^{\circ}$ ano e 37 no $9^{\circ}$ ano. No $2^{\circ}$ ano não foi aplicado questionário porque os alunos ainda não eram alfabetizados. Ao todo, participaram da pesquisa 143 alunos do Ensino Fundamental, sendo 35 do $2^{\circ}$ ano, 33 do $4^{\circ}$ ano, 38 do $6^{\circ}$ ano e 37 do $9^{\circ}$ ano, 36 professores, totalizando 179 participantes investigados.

\section{RESULTADOS E DISCUSSÃO}

Encontra-se estabelecido no PPP da escola a disciplina de Educação Ambiental, específica, com abrangência do $6^{\circ}$ ao $9^{\circ}$ ano do Ensino Fundamental. Ressalta-se que, embora não se apresentem na grade curricular do PPP os pressupostos teóricos do ensino de EA para as turmas do $1^{\circ}$ ao $5^{\circ}$ ano, existe na escola a disciplina de EA para as referidas séries. A disciplina é apresentada como o encaminhamento metodológico que visa educar os alunos para que ajam de forma responsável e com sensibilidade, conservando o

Revbea, Rio Grande, V. 8, № 1:30-41, 2013. 
ambiente saudável no presente e para o futuro.

Isso demonstra que o PPP privilegia uma abordagem que incentiva a sensibilidade, o saber científico, mas também a emoção e sentimentos dos alunos, com vistas a garantir mudanças de comportamento em relação ao meio ambiente, embora de certa forma contrarie o que é proposto pelos PCNs, ou seja, o trabalho de EA em parceria com outras disciplinas, de maneira interdisciplinar.

A justificativa para existir uma disciplina de EA na escola se baseia no direcionamento do Artigo 26 da LDB/9394/96, que explicita:

Art. 26. Os currículos de ensino fundamental e médio devem ter um base nacional comum, a ser complementada em cada sistema de ensino e estabelecimento escolar, por uma parte diversificada exigida pelas características regionais e locais da sociedade, da cultura, da economia e da clientela. (BRASIL, 1996, p.11).

Embasada nesse artigo que orienta que cada escola pode estabelecer disciplinas diversificadas em seu currículo, de acordo com as características regionais e locais, é que a escola optou por inserir a E.A na grade curricular, a fim de atender às exigências de características regionais e locais, mas o fato de existir uma disciplina especifica de EA orientada pelo próprio PPP contraria as orientações da lei 9795/99 e dos Parâmetros Curriculares Nacionais, os quais estabelecem que a educação ambiental deva ser inserida no ensino em interface com as demais disciplinas e não numa disciplina específica.

A Lei $9795 / 99$ no art. $10^{\circ}$ estabelece que:

Art. 10. A educação ambiental será desenvolvida como uma prática educativa integrada, contínua e permanente em todos os níveis e modalidades do ensino formal. § 10 A educação ambiental não deve ser implantada como disciplina específica no currículo de ensino (BRASIL, 1999, p.3).

Nas escolas, os conteúdos de meio ambiente devem ser unificados ao currículo escolar através da transversalidade. Os Parâmetros Curriculares Nacionais sobre Temas Transversais (1998a, p. 193) afirma o seguinte quanto à necessidade da transversalidade no tema Meio Ambiente:

Os conteúdos de Meio Ambiente foram integrados às áreas, numa relação de transversalidade, de modo que impregne toda a prática educativa e, ao mesmo tempo, crie uma visão global e abrangente da questão ambiental, visualizando os aspectos físicos e histórico-sociais, assim como as articulações entre a escala local e planetária desses problemas. 
Nesse contexto, nota-se que a opção por privilegiar a discussão da EA numa disciplina específica se constitui, em vez de ganho, como um retrocesso, contribuindo para seu isolamento como saber que não atravessa outras áreas de conhecimento. Assim, a disciplinarização pode incentivar as demais disciplinas a ignorar o trato da EA na prática de ensino por entender que já existe conteúdo específico para tal abordagem.

O tema meio ambiente deve ser abordado em todas as áreas do conhecimento, de forma a estabelecer em todo o âmbito escolar a prática do ensino interdisciplinar, ou seja, instituir uma visão global e abrangente das questões ambientais, utilizando o diálogo dos saberes entre todas as disciplinas do currículo.

Segundo Reigota (2004, p.79):

A educação ambiental correu o risco de se tornar, por decreto, uma disciplina obrigatória no currículo nacional, mas o que os burocratas e oportunistas de plantão não contavam era encontrar a resistência dos profissionais mais conhecidos da área, evitando assim que se transformasse em mais uma banalidade pedagógica, perdendo todo o seu potencial crítico e questionador das nossas relações cotidianas com a natureza, artes, conhecimentos, ciência, instituições, trabalho e com as pessoas que nos cercam.

Mediante essas considerações, essa investigação aponta que o PPP da escola pesquisada não se encontra em total acordo com o que determina os documentos oficiais em relação à $E A$, especialmente a Lei 9795/99, que estabelece a não implantação de uma disciplina específica de EA no currículo de ensino. Por sua vez, a proposta de transversalidade prevista nos PCNs é contemplada pelo PPP da escola, visto que inclui o meio ambiente no currículo escolar como tema transversal, embora não proponha ações específicas de $E A$. Este documento também não esclarece como devem ser ministrados os conteúdos de EA, cabendo a cada professor, inclusive o da disciplina específica, desenvolver seu próprio planejamento ou projetos que se encaixem no eixo norteador da disciplina.

\section{A VOZ DOS PROFESSORES}

O professor é o profissional que se coloca na linha de frente das práticas da EA no ensino formal, sendo, portanto, o protagonista das transformações curriculares (MEDINA, 1995) e da incorporação da EA dentro da Escola. Assim, é importante conhecer a visão desses profissionais sobre meio ambiente, planejamento de atividades de EA, percepção do envolvimento da escola, alunos e comunidade com as atividades da EA.

Em relação aos temas transversais trabalhados em sala, a maior parte de educadores $32 \%$ afirmou ser o meio ambiente o tema mais trabalhado,

Revbea, Rio Grande, V. 8, № 1:30-41, 2013. 
seguido pela pluralidade cultural $18 \%$, ética $16 \%$, saúde $14 \%$, trabalho e consumo $14 \%$, estando em último lugar à orientação sexual $6 \%$. Sendo assim, percebemos que, segundo o lugar de fala dos professores, o tema ambiental é trabalhado como tema transversal em suas aulas.

A fim de analisar como os educadores compreendem o conceito de meio ambiente, a pesquisa elaborou-lhes a questão: $O$ que você entende por meio ambiente? As respostas aqui apresentadas foram elencadas seguindo os conceitos de meio ambiente como: 1) recurso a ser explorado economicamente; 2) um problema a ser resolvido; 3) projeto comunitário em que todos são envolvidos; 4) natureza para ser apreciada, respeitada e preservada.

Das 16 respostas obtidas, apenas uma assinalou o meio ambiente como natureza a ser respeitada e preservada: "é tudo que envolve os seres vivos e que temos o dever de defender e preservar"; as demais respostas sistematizadas por semelhança atendem ao conceito de meio ambiente como um projeto comunitário em que todos somos envolvidos.

$\mathrm{Na}$ perspectiva da $A D$, o discurso dos professores, referente ao que entendem por meio ambiente, se organiza em duas linhas: uma descrição sobre o que é e a enunciação de uma preocupação com sua preservação. Embora bastante vagas e genéricas, as afirmações deixam transparecer a existência da incorporação, ao menos no âmbito de um saber, da preservação ambiental. Essa perspectiva cognitiva parece ser o que orienta as práticas escolares: apesar do PPP indicar uma orientação para o trato sensível, a EA não se constitui no diálogo com um fazer, mas um saber ainda dissociado de uma prática, de um engajamento. A escola pode falar sobre a coleta seletiva, mas não se dispõe a praticá-la.

Conforme respostas dos docentes o meio ambiente foi o tema transversal mais recorrente em sala de aula, a pesquisa questiona como se dá a inclusão da temática nas disciplinas. Nesta questão $69 \%$ dos entrevistados garantiram tratar 0 tema de forma interdisciplinar, sistematicamente intercalando-o com a produção de textos, poemas ou artes, pesquisas audiovisuais e mediante projetos de entidades parceiras e realização de palestras de conscientização.

Ao buscar verificar a interdisciplinaridade no trato com a temática ambiental entre as disciplinas, observando os níveis de interdisciplinaridade demonstradas por Fazenda (1994), que a considera uma interação entre as disciplinas - caracterizada pela presença de uma axiomática comum, definida no nível hierárquico imediatamente superior; e a fundamentação de interdisciplinaridade preconizada nos PCNs que a tratam como "eixo integrador que pode ser o objeto de conhecimento, um projeto de investigação, um plano de intervenção" (BRASIL, 1998b, p.88-89), a pesquisa constata que a interdisciplinaridade existe, embora em um nível de interação embrionário, fragmentado.

É importante ressaltar, conforme Fazenda (1998), que o campo da 
interdisciplinaridade não é único nem estável, visto que se constroi sob diferentes níveis e varia a sua interpretação conforme vai sendo apropriado pelos processos educativos. Dessa ausência de consenso, em torno do próprio conceito de interdisciplinaridade, surgem as dificuldades iniciais por parte da escola pesquisada em realizar um trabalho interdisciplinar satisfatório, pois é possível notar que existe desde uma simplificação do termo à redução de propostas e atividades corriqueiras de coordenação entre diferentes disciplinas.

Quando a interdisciplinaridade se refere à questão ambiental, Leff (2001, p.115) defende que ela não pode ser vista como somatória nem como articulação de disciplinas, "menos ainda se dá à margem destas". O autor explicita que:

O ensino interdisciplinar no campo ambiental implica na construção de novos saberes, técnicas e conhecimentos e a sua incorporação como conteúdos integrados no processo de formação. Ele requer um processo de autoformação e a formação coletiva da equipe de professores, quanto à troca sobre diversas temáticas ambientais, de elaboração de estratégias docentes e definição de novas estruturas curriculares. (LEFF, 2001, p.115).

Neste aspecto, a pesquisa constatou, mediante respostas dos próprios docentes que deveria ser costumeiro ocorrer planejamento conjunto dos conteúdos, mas isso não ocorre como deveria, pois muitos professores não planejam conjuntamente por falta de tempo, enquanto outros não o fazem simplesmente por vaidade, por não aceitarem sugestões e críticas de seus pares. Ressalta-se que, no início de cada ano letivo a escola, através da coordenação pedagógica, realiza uma semana de planejamento conjunto (chamado de planejamento anual), quando todos os professores da escola realizam seus planos de aulas com seus pares de outras disciplinas.

Durante o decorrer do ano letivo ocorre o planejamento semanal, entre os professores de uma mesma série, evidenciou-se que os planejamentos semanais geralmente eram para que os professores das séries idênticas pudessem ensinar os mesmo conteúdos de forma conjunta. O que sugere a falta de um verdadeiro planejamento semanal incluindo todos os professores das disciplinas ministradas do currículo escolar, para que fosse estabelecido um diálogo efetivo e permanente entre as disciplinas. Portanto o planejamento semanal para a maioria dos professores é realizado individualmente.

Esse fato corrobora as afirmações de Silva e Pinto $(2009$, p. 8) quando declaram que "as discussões sobre a interdisciplinaridade são registradas de modo mais enfático no nível dos fundamentos legais", mas no âmbito das orientações pedagógicas para a sala de aula se mostram pouco presentes.

Sendo a Educação um instrumento de transformações comportamentais, buscou-se identificar se os professores observam mudanças de atitudes dos alunos em função das atividades que envolvem a EA na escola.

Revbea, Rio Grande, V. 8, № 1:30-41, 2013. 
Como resposta, $50 \%$ dos entrevistados garantem ser possível identificar mudança de atitude dos alunos em relação ao meio ambiente, enquanto que $50 \%$ identificam que essa mudança é evidenciada apenas em alguns aspectos, parcialmente.

Para exemplificar esses resultados positivos, os professores citaram as seguintes mudanças de atitudes dos alunos: o cuidado com o meio ambiente, não jogando lixo no chão, economia de água e energia e o manuseio com o lixo. Essas observações inclusive foram endossadas pelos próprios alunos.

No entanto, os educadores salientam que tais atitudes são mais comuns nas últimas séries do Ensino Fundamental, visto que a conscientização ambiental aumenta à medida que os alunos crescem. Os professores aproveitaram para apontar a necessidade de se trabalhar de modo mais abrangente a temática ambiental mediante incentivos e melhor estruturação da escola a fim de se atingir resultados não apenas parciais, mas integrais na formação de alunos ecologicamente conscientes.

Pode-se entender, diante dessa resposta dos professores e mediante as observações feitas em aula, que a EA vem lentamente surtindo seus efeitos positivos, contudo os professores ressalvam que há na escola insuficiência de materiais didáticos próprios para desenvolver trabalhos de $E A$, visto que praticamente eles só tenham à disposição o livro didático como material de apoio.

A utilização integral do livro didático não é satisfatória porque os conteúdos precisam ser trabalhados sob diferentes olhares, com gêneros textuais variados, por exemplo. Ademais, alguns livros costumam confundir a EA com ecologia, trazem um enfoque utilitarista da natureza e abordam problemas ambientais de modo fragmentado, enfatizando mais as consequências do que as causas e soluções, quando não trazem explícita ou implicitamente padrões culturais que reforçam o antropocentrismo (GRUN, 1994).

\section{A VOZ DOS ALUNOS}

Questionados se em sala havia discussões mediadas pelos professores sobre assuntos relacionados a meio ambiente, $80 \%$ dos alunos confirmam a versão dos professores quando relatam existir esse debate em sala, sendo acompanhados por (18\%) que afirmam quase sempre haver.

A pesquisa buscou saber o que os alunos entendem por meio ambiente e a exemplo dos professores, as respostas foram sistematizadas considerandose as opções: a) recurso para ser explorado economicamente; b) um problema a ser resolvido; c) projeto comunitário em que todos somos envolvidos; d) Ambiente como natureza para ser apreciado, respeitado e preservado.

No $4^{\circ}$ ano do Ensino Fundamental, todas as respostas evidenciaram uma concepção de meio ambiente pautada no aspecto físico e biológico como: "tudo que esta à nossa volta ou redor". 
Interessante notar que, apesar de os professores responderem a essa pergunta de modo mais elaborado, a concepção de meio ambiente deles é a mesma apresentada por estes estudantes, pautada num aspecto naturalista, sem considerar os outros desdobramentos que a temática encerra quanto aos aspectos políticos, sociais, econômicos e ambientais.

No 6ํaㅅ ano, embora algumas respostas sobre a mesma questão ainda se atenham à concepção de meio ambiente físico, parcela considerável de alunos o veem como um lugar a ser preservado, uma concepção que já atende ao discurso da sustentabilidade, que traz como um dos tripés a questão da degradação ambiental, desdobramento bem mais complexo que apenas o considerá-lo ambiente físico, próprio para se viver.

As respostas à questão no $9^{\circ}$ ano demonstram que os alunos entendem ser o meio ambiente um lugar a ser preservado, uma concepção de meio ambiente apenas físico, além de suscitar descaso e desinteresse para alguns.

As respostas apresentadas pelos alunos vão ao encontro com o princípio de EA defendida por Reigota (2004, p. 10), que a apresenta como "uma proposta que altera profundamente a educação que conhecemos, a qual é configurada como uma prática pedagógica voltada para a transmissão de conhecimentos sobre ecologia". Segundo o autor, essa nova proposta trata "de uma educação que visa não só pela utilização racional dos recursos naturais, mas basicamente a participação dos cidadãos nas discussões e decisões sobre a questão ambiental". (REIGOTA, 2004, p.11).

Em relação às disciplinas em que a temática meio ambiente é mais abordada, foram apontadas, na ordem: Educação Ambiental 73\%; Ciências, com 57\%; Geografia, com 38\%.

A investigação buscou analisar se os alunos consideram importante discutir temas ambientais na escola. Nas três turmas pesquisadas $83 \%$ dos alunos defendem a importância da temática ambiental contra $12 \%$ dos estudantes que são indiferentes à questão, 4\% dos alunos, por sua vez, afirmaram não ser necessário tratar de temas ambientais em sala de aula.

Embora quantidade superior de alunos defenda a importância de se discutir a temática ambiental na escola, nota-se que a ausência do entendimento de que a formação de uma consciência ambiental é essencial para a garantia de preservação da vida na terra ainda é notória entre os estudantes e isso, conforme Bakhtin (1995) encontra-se diretamente relacionadas às percepções, aos processos cognitivos, julgamentos e expectativas de cada indivíduo. Nesta perspectiva, ao se considerar que a constituição da consciência individual e da subjetividade se elabora mediante determinadas condições históricas e relações sociais, a percepção ambiental resulta também de sentidos históricos e socialmente compartilhados, mobilizados pelos sujeitos (alunos) nesse contexto escolar.

Os alunos entrevistados afirmaram em questão aberta que os principais problemas ambientais considerados graves na atualidade, entre Revbea, Rio Grande, V. 8, Nº 1:30-41, 2013. 
outros, são por ordem de urgência: poluição, queimadas, lixo e desperdício de água. Nesse contexto, a investigação se propôs a delinear a percepção que os estudantes têm em relação ao meio ambiente. Entre as respostas, a que maior pontuação recebeu (48\% das respostas) foi a vertente que considera o meio ambiente como natureza para ser apreciado, respeitado e preservado.

Diante disso, verifica-se um paradoxo entre o que os alunos responderam sobre o que entendiam por meio ambiente e a vertente escolhida por eles nesta pergunta. Na primeira questão, com exceções, parcela significativa de estudantes concebeu o meio ambiente sob o aspecto naturalista, físico e utilitarista; já na segunda questão, eles o concebem como natureza a ser apreciada e preservada. O que se pode concluir a partir dessas respostas é que os alunos compreendem a complexidade que envolve 0 conceito de meio ambiente e no momento que precisam se expressar sobre a temática, utilizam-se de discursos já institucionalizados no senso comum, não havendo da parte deles uma preocupação em racionalizar e elaborar uma resposta, a percepção individual passa a ser socialmente compartilhada.

Nota-se por essas afirmativas, que embora algumas questões respondidas no questionário por professores e alunos demonstrem um ensino de Educação Ambiental embrionário, a escola tem contribuído para a formação de sua consciência ecológica, mas de forma contraditória. Nessa perspectiva, o que se pode apontar é que a complexidade que envolve a EA resulta em dificuldades de se elaborar desdobramentos desse conceito, na comunidade escolar.

\section{CONSIDERAÇÕES FINAIS}

Esta pesquisa entende que no ensino formal nas escolas a educação ambiental deve seguir o padrão estabelecido pelos PCNs e PRONEA, que é reiterado por Reigota (2004), no sentido de que a EA deva ser edificada como uma filosofia educacional que esteja presente em todas as disciplinas, de forma interdisciplinar e transversal, não se constituindo em disciplina, para que, dessa forma, seja alcançada uma visão holística na escola, inserindo e engajando os alunos em seu contexto sócio-histórico local e planetário.

Ao criar uma disciplina específica para a EA, a escola reproduz um discurso de resistência às propostas dos principais documentos que orientam as discussões sobre o ambiente e coloca em risco seu papel como instituição escolar voltada à construção de valores, conhecimentos e práticas ligados à sustentabilidade, um dos desdobramentos da EA. A responsabilidade social da escola do Século XXI demanda das instituições de ensino uma reformulação no currículo, com uma efetiva reorganização das disciplinas e da didática, incluindo a inserção da EA nos conteúdos tradicionais e nos Projetos PolíticoPedagógicos (PPP) da escola, de forma inter e transdisciplinar, procurando formar um cidadão consciente de que uma construção individual e coletiva depende de elementos não apenas biofísicos, mas também sociais (LEFF, 2001) e que existem e funcionam como um todo complexo e interacional.

Revbea, Rio Grande, V. 8, N 1:30-41, 2013.

revista brasileira 
Constatou-se que, apesar dos sujeitos da pesquisa atribuírem uma grande importância ao Meio Ambiente e expressarem um grau considerável de consciência ambiental, o envolvimento na prática ainda é insuficiente.

Mesmo assim, a pesquisa constatou exemplos positivos de mudança dos alunos em relação ao trato com o meio ambiente, relatados por eles mesmos no questionário, o que atesta que as concepções de $E A$ foram transmitidas pela escola e reelaboradas por estes alunos, mesmo considerando todas as fragilidades dessa prática na escola. É preciso lembrar, entretanto, que outros recursos informais de EA, principalmente os midiáticos, podem haver contribuído para os resultados observados.

A pesquisa aponta que a escola não pode ser a única responsável pela formação da consciência ambiental. A EA surgiu como uma aposta para se alcançar as mudanças de atitudes necessárias para a solução dos graves problemas ambientais que o mundo vivência, porém não conseguirá cumprir essa tão importante missão sozinha. Para tanto, é necessário elaboração de políticas públicas que tenham uma dimensão participativo-consultiva, baseada nos pilares da co-gestão e da co-responsabilidade, envolvendo o Estado, a escola, a família, a iniciativa privada e as organizações não governamentais, expandindo a EA para além dos muros da escola.

\section{REFERÊNCIAS}

BAKHTIN, M. Marxismo e filosofia da linguagem. 7. ed. São Paulo: Hucitec, 1995.

BRASIL. Lei de Diretrizes e Bases da Educação 9.394/96. Brasília, DF: MEC, 1996. Disponível em: <http://portal.mec.gov.br/arquivos/pdf/ldb.pdf >. Acesso em: 05 jun. 2010.

BRASIL. Ministério da Educação. Secretaria de Ensino Fundamental. Parâmetros Curriculares Nacionais - Documento Introdutório. Brasília, DF: Ministério da Educação, 1997.

BRASIL. Secretaria de Educação Fundamental. Parâmetros Curriculares Nacionais - Introdução. 5a a 8 8 $^{\mathbf{a}}$ Séries - Temas Transversais. v.9. Meio Ambiente e Saúde, 1998a.

BRASIL. Secretaria de Educação Fundamental. Parâmetros Curriculares Nacionais: terceiro e quarto ciclos do ensino fundamental. Brasília, DF: MEC/SEF, 1998b.

BRASIL. Lei no 9795, de 27 abr. 1999. Dispõe sobre a educação ambiental, institui a Política Nacional de Educação Ambiental (PRONEA) e dá outras providências. em: $<$ http://www.embasa.ba.gov.br/legislacao/Lei9795de27-0499 EducacaoAmbiental.pdf>. Acesso em: 11 out. 2010. 
BRASIL. Constituição Federal do Brasil. Brasília: Senado, 2006.

COSTA, G. R. Constituição do sujeito enunciador do GESTAR II. Rev. Interdisciplinar, Universidade Federal de Sergipe, ano IV, v.9, p. 119-128, ago./dez. 2009.

FAZENDA, I.C.A. Interdisciplinaridade: história, teoria e pesquisa. 6. ed. Campinas: Papirus, 1994.

FAZENDA, I.C.A. (Org.) Didática e interdisciplinaridade. Campinas: Papirus, 1998.

GRUN, M. Uma discussão sobre valores éticos em Educação Ambiental. Educação e Realidade, Porto Alegre, v. 19, p. 171-198, 1994.

LEFF, E. Saber ambiental: sustentabilidade, racionalidade, complexidade, poder, Petrópolis, RJ: Ed. Vozes, 2001.

MEDINA, C. A. Entrevista: o diálogo possível. São Paulo: Ática, 1995.

PÊCHEUX, M. Semântica e discurso: uma crítica à afirmação do óbvio. 2. ed. Campinas: UNICAMP, 1995.

REIGOTA, M. Meio ambiente e representação social. São Paulo: Cortez, 2004.

SILVA, L. H. O; PINTO, F. N. P. Interdisciplinaridade: as práticas possíveis. Revista Querubim, v. 5, p. 01-18, 2009. Disponível em: $<$ http://www.uff.br/feuffrevistaquerubim/images/arquivos/artigos/interdisciplinarid ade entre teorias e prticas.pdf>. Acesso em: 20 maio 2010. 